\title{
The conservation research-practice gap: a case study of a threatened bird
}

\author{
Cristian Pérez-Granados and Germán M. López-Iborra
}

\begin{abstract}
Conservation research is less often applied in practice than is desirable for the optimization of conservation outcomes. We evaluated this conservation researchpractice gap for a threatened passerine, Dupont's lark Chersophilus duponti. We reviewed the literature and classified the conservation interventions proposed by scientists as regulation and legislation, monitoring and research, or management. We sent a questionnaire to managers responsible for species conservation, to gather information about the reasons for implementing, or not, each conservation intervention. We found 16 conservation interventions proposed in the literature, of which $13(81.2 \%)$ had been applied by managers at least once. We found a disparity between the frequency of scientific recommendations and the actions implemented by managers: some measures with high scientific consensus were rarely adopted, whereas approaches less frequently proposed by scientists were more often implemented by managers. Regulatory and monitoring/research interventions were applied more often than management interventions, probably because of legal obligations. Management interventions were less frequently implemented, mainly because of time and budget limitations. There was a negative correlation between the number of interventions implemented and the population trend of the species in each region, which suggests that conservation interventions were more commonly implemented when the species was facing local extinction. Our results indicate a mismatch between science and practice for the conservation of Dupont's lark, the reasons for which seem to be diverse and include factors such as financial and time limitations, legal obstacles and managers' perception of extinction risk. An iterative dialogue needs to be initiated between scientists and managers to evaluate the efficacy of interventions implemented, and facilitate evidence-based conservation.
\end{abstract}

Keywords Chersophilus duponti, conservation biology, conservation intervention, Dupont's lark, evidence-based conservation, managers, science-practice divide

Cristian Pérez-Granados* (Corresponding author, (D) orcid.org/0000-00033247-4182) and Germán M. López-IborRa (@ orcid.org/0000-0003-3045-5498) Ecology Department/IMEM 'Ramón Margalef', Universidad de Alicante, 03690, Alicante, Spain. E-mail cristian.perez@ua.es

${ }^{*}$ Also at: National Institute for Science and Technology in Wetlands, Federal University of Mato Grosso, Computational Bioacoustics Research Unit, Cuiabá, Mato Grosso, Brazil

Received 30 October 2019. Revision requested 20 December 2019.

Accepted 25 March 2020. First published online 26 February 2021.
Supplementary material for this article is available at doi.org/10.1017/So03060532000023X

\section{Introduction}

onservation biology seeks to provide the best available $\checkmark$ data to managers, with guidelines and recommendations for the practical management of threatened ecosystems, habitats and species (Fazey et al., 2005). However, conservationists have been concerned about the potentially tenuous role that their research plays in policy-making and management. Conservation science is rarely translated into conservation actions (Gibbons et al., 2011), a phenomenon known as the research-practice gap (Fazey et al., 2005; Knight et al., 2008; Fabian et al., 2019). Several reasons have been proposed to explain the gap (Matzek et al., 2014), but there is agreement that one of the main causes is limited interaction between scientists and managers (Sutherland et al., 2009; Toomey et al., 2017). Even if managers consider scientific literature as a valuable conservation tool, lack of time to read and synthesize information (Sutherland et al., 2013), and the cost of accessing literature, can be strong barriers to engagement with current research, thus widening the conservation research-practice gap (Pullin \& Knight, 2005; Matzek et al., 2014).

Managers obtain information on which to base their decisions from a wide range of sources (Cook et al., 2013), and often rely on their own experience and that of their colleagues at other management agencies (Sutherland et al., 2004; Matzek et al., 2014). The challenges in using conservation science to guide practice have contributed to the poor use of empirical evidence to inform management decisions, despite the fact that an evidence-based approach to conservation is clearly desirable (Sutherland et al., 2004; Legge, 2015). On the other hand, some conservation measures proposed by scientists are educated guesses that have never been put into practice. When such measures are considered and applied by managers, their adequacy is rarely assessed through monitoring (Bottrill \& Pressey, 2012), but such evaluation is critical for inspiring confidence amongst decision makers that the costs of conservation actions are justified (Gibbons et al., 2011). In addition, experience or anecdote often guides managers' decisions even when scientific evidence is available (Sutherland et al., 2004; Cook et al., 2010). In this context, concerns arise as to how relevant scientific literature is to practitioners (Gossa et al., 2015). Why 
are some conservation measures considered and applied by managers and others are not?

We used Dupont's lark Chersophilus duponti as a case study to address this question. Its European population, restricted to Spain, has been estimated to be c. 2,200 pairs (Suárez, 2010). Despite the scientific effort invested (Suárez, 2010; Pérez-Granados \& López-Iborra, 2018), the population is declining, with several subpopulations having gone extinct and an overall 41.4\% decline during 2004-2015 (Gómez-Catasús et al., 2018). On the IUCN Red List, the species is categorized as Vulnerable (BirdLife International, 2020). The decline of the species may be the result of the inefficient or non-existent implementation of conservation measures proposed by scientists. However, there are no prior assessments about how often and which types of conservation interventions proposed by scientists are implemented by practitioners, or the effectiveness of such measures.

Here, we used Dupont's lark as study model, with our main goal being to examine the extent of the gap between measures recommended by scientists and those implemented by managers for the conservation of this threatened passerine. We identified the conservation interventions proposed in the literature and reviewed the interventions actually implemented for protecting the species, and the reasons declared by conservation managers for the implementation, or not, of each intervention. This assessment is fundamental for identifying the obstacles that hinder the recovery of Dupont's lark. In addition, an understanding of this matter could help address similar problems for the conservation of other species.

\section{Methods}

\section{Literature review and questionnaire}

We investigated the conservation research-practice gap for Dupont's lark through a literature review and a questionnaire sent to practitioners. We reviewed the published studies on Dupont's lark that recommend at least one conservation intervention. To identify relevant studies, we searched the Web of Science (Clarivate Analytics, Philadelphia, USA) and Google Scholar (Google, Mountain View, USA) on 4 January 2018, spanning all years and all subject areas and using the keywords: alondra de Dupont OR alondra ricotí OR Chersophilus duponti OR Dupont's lark. We also checked references included in the publications that we had identified with these searches.

We gathered the following information for each publication: (1) authorship (understood as the institutional affiliation of the first author), used to estimate the number of times that each conservation measure was independently proposed, (2) main aim of the study, to avoid including papers that did not focus on the conservation of Dupont's lark, and (3) conservation interventions proposed. We considered the number of times that a conservation measure was proposed as an indicator of the scientific consensus for recommending its implementation and testing its effectiveness.

We defined a conservation intervention as any repeatable approach that identifies actions that should be implemented to increase the likelihood of conserving the species. Conservation interventions were divided into three categories: (1) management interventions, defined as manipulative, purposeful actions performed on the species or its habitat, such as habitat management or captive breeding, (2) monitoring and research measures, defined as research to obtain data required for management decisions, such as population monitoring or research on the species' ecology, and (3) regulation and legislation interventions, understood as measures that define acceptable or unacceptable actions or promote management activities, such as regulations on land-use transformation, or protection of populations under a specific conservation category.

To evaluate the number of conservation interventions that were actually implemented, on 10 January 2018 we sent an online questionnaire (Supplementary Material 1) to the heads of biodiversity conservation departments in regional governments of all eight regions that harbour Dupont's lark populations (one questionnaire per region). All authorities replied to the questionnaire and agreed to include the region's name in the results. According to Spanish legislation, regional governments are responsible for species conservation and are the only authorities that have the competence to develop and implement conservation interventions in terrestrial ecosystems. The questionnaire included a list of the conservation interventions proposed by scientists, from our literature review, and an open question about the implementation of conservation interventions not included in the list. We used this information to identify the number and type of conservation measures conducted in each region. For each conservation intervention implemented we asked if the efficacy had been evaluated. Finally, we asked about the motivations for implementing, or not, each intervention. We provided a list of eight reasons to choose from regarding why it was decided to implement an intervention, and a list of 10 reasons for not implementing interventions (Supplementary Material 1). Respondents could choose multiple answers for each question. An open field was also included, allowing respondents to add reasons that were not included in the questionnaire (Supplementary Material 1). Respondents added two reasons ('Need for a population index' and 'Due to population decline') to explain their choice to implement a conservation intervention, and a variety of additional motivations for not implementing interventions. We examined these additional answers and grouped them into two new categories: 'in process' when the actions needed to implement a conservation intervention had begun but the intervention had not yet been 
put into practice, and 'elusive answer' when the connection between the reason given and the question asked was unclear.

\section{Statistical analyses}

To identify gradients of reasons that determined whether a type of conservation action was implemented or not, we calculated two matrices of reasons (variables) given for implementing, or not, each conservation intervention (rows). We built each matrix by counting the number of times that each reason was declared for each conservation intervention. We then calculated the per cent that each reason represented of the total number of reasons cited for each conservation measure. In both matrices, we excluded those actions implemented, or not, in only one region. Percentages were transformed using the arcsine of the square root, and each matrix was analysed using principal component analysis (PCA; Dormann et al., 2013) based on a variance-covariance matrix. PCAs were carried out using the $r d a$ function in the $R$ package vegan (Oksanen et al., 2007). Eigenvalues for each principal component were compared to broken-stick model eigenvalues to identify useful principal components (Jackson, 1993). We calculated correlations between arcsine transformed per cent that each reason was declared by managers and the resulting PCA axis and used those with $\mathrm{P}<0.1$ to interpret PCA gradients. Data analyses were conducted in $R$ 3.4.1 (R Development Core Team, 2014).

\section{Results}

We identified 89 articles in the literature review, but excluded 44 because they did not describe conservation measures or were carried out in North Africa, where we did not collect data about conservation practices. In the remaining 45 articles, we identified 16 conservation interventions: six management interventions, six regulation and legislation measures and four monitoring and research interventions (Table 1, Supplementary Table 1). Regulation and legislation measures were the conservation interventions most often proposed by scientists ( 57 times, $44.9 \%$ of the total number of interventions proposed), followed by management interventions ( 53 times, $41.7 \%$ ) and monitoring and research interventions ( 17 times, $13.4 \%$; Table 1 ). There was a strong correlation between the number of articles proposing each conservation intervention and the number of scientific institutions (by affiliation of the first author) that recommended each action (Spearman's correlation coefficient $=0.968$; $\mathrm{P}<0.001$ ).

The eight regions had each implemented 2-12 conservation interventions (Table 2, Supplementary Table 2). Overall, 13 types of conservation interventions were implemented at least once, totalling 54 actions taken to protect
Dupont's lark in Spain (Table 1, Supplementary Table 2). Monitoring and research interventions were the conservation interventions most often implemented by managers (all four types of interventions proposed were implemented a total of 27 times, $50 \%$ of the total number of actions taken), followed by regulation and legislation measures (five of the six types of interventions proposed were implemented a total of 16 times, 29.6\%), and management interventions (four of the six interventions proposed were executed a total of 11 times, 20.4\%). However, three conservation interventions were never executed and four were implemented only once (Table 1 , Supplementary Table 2 ). No region implemented conservation interventions not included in the list provided. After excluding the conservation intervention defined as 'Evaluate efficacy of conservation assessments', we found that the efficacy of actions implemented was evaluated in 26 of the 47 interventions performed (55.3\%), with no significant difference in the percentage of interventions evaluated between the three categories of interventions $\left(\chi^{2}=2.59, \mathrm{df}=2, \mathrm{P}=0.27\right)$. However, the efficacy of two of the interventions implemented ('Increase available habitat' and 'Protect marginal habitats') was never tested. There was no correlation between the frequency with which a certain conservation intervention was implemented by each authority and how frequently it was proposed by scientists (Spearman's correlation coefficient $=0.089 ; \mathrm{P}=0.744$; Table 1 ).

We used the first two PCA axes to summarize the reasons for implementing conservation interventions (Supplementary Table 3, summary of PCA in Supplementary Table 5). PCA I (45.9\% of total variance) was most positively correlated with legal obligation and secondly with personal beliefs that the intervention would improve the conservation status of the species. PCA II (27.9\% of total variance) separated conservation interventions between those most often implemented because of proven success, previous experience and literature review (positive coordinates) against measures implemented when a budget was available (negative coordinates). There is a clear separation of the three types of measures on PCA I. Implementation of regulation and legislation interventions was clearly associated with legal obligation (positive coordinates), whereas management interventions were never implemented for this reason. The main motivation for management interventions was scientific advice, which was negatively but not significantly correlated with PCA I. Monitoring and research interventions had variable positions on this axis, because developing a precise counting method for population estimates was based on scientific advice, whereas the main reason given for the remaining interventions was legal obligation, although scientific advice was also mentioned (Fig. 1). Regulation and legislation interventions were highly variable along PCA II, reflecting differences in other reasons beyond legal obligation. Proven success and previous experience were reasons given for preventing negative actions and protecting populations under a conservation category, and budget 
TABLE 1 Conservation measures proposed in the scientific literature for Dupont's lark Chersophilus duponti, ranked by number of articles (and per cent of the total of 45 articles) in which the proposal appears. The type of conservation intervention, number of different scientific institutions that proposed each action (and per cent of the total of 15 institutions), and number of regions where conservation measures have been implemented, are also shown.

\begin{tabular}{|c|c|c|c|c|}
\hline Conservation measure & Type $^{1}$ & $\begin{array}{l}\text { No. of } \\
\text { articles (\%) }\end{array}$ & $\begin{array}{l}\text { No. of } \\
\text { institutions (\%) }\end{array}$ & $\begin{array}{l}\text { No. of } \\
\text { regions where } \\
\text { implemented }\end{array}$ \\
\hline Protect populations under a conservation category $(\mathrm{IBA}, \mathrm{SPA})^{2}$ & RL & $18(40.0)$ & $10(66.7)$ & 7 \\
\hline $\begin{array}{l}\text { Prevent negative actions (infrastructure, reforestation, etc.) in the } \\
\text { species' occupation area }\end{array}$ & $\mathrm{RL}$ & $17(37.8)$ & $8(53.3)$ & 5 \\
\hline Promote extensive grazing to maintain optimal vegetation structure & M & $15(33.3)$ & $6(40.0)$ & 3 \\
\hline $\begin{array}{l}\text { Reduce isolation of fragmented populations by establishing habitat } \\
\text { corridors }\end{array}$ & M & $14(31.1)$ & $6(40.0)$ & 0 \\
\hline $\begin{array}{l}\text { Increase available habitat in areas where the species is not currently } \\
\text { present }\end{array}$ & M & $11(24.4)$ & $5(33.3)$ & 1 \\
\hline Habitat management in occupied areas to improve habitat quality & M & $11(24.4)$ & $6(40.0)$ & 6 \\
\hline $\begin{array}{l}\text { Long-term population monitoring for information about population } \\
\text { sizes \& trends }\end{array}$ & MR & $8(17.8)$ & $5(33.3)$ & 7 \\
\hline $\begin{array}{l}\text { Increase threat category to ensure the protection of the species in } \\
\text { its distribution range }\end{array}$ & $\mathrm{RL}$ & $7(15.6)$ & $5(33.3)$ & 0 \\
\hline Develop a conservation action plan & RL & $7(15.6)$ & $4(26.7)$ & 1 \\
\hline Increase biological knowledge about the species & MR & $7(15.6)$ & $3(20.0)$ & 5 \\
\hline $\begin{array}{l}\text { Environmental education to ensure future protection \& increase } \\
\text { public awareness }\end{array}$ & $\mathrm{RL}$ & $6(13.3)$ & $4(26.7)$ & 1 \\
\hline $\begin{array}{l}\text { Protect marginal habitats that may be used during post-breeding } \\
\text { season }\end{array}$ & $\mathrm{RL}$ & $2(4.4)$ & $1(6.7)$ & 2 \\
\hline Create a precise census method for comparable results & MR & $1(2.2)$ & $1(6.7)$ & 8 \\
\hline Evaluate efficacy of conservation assessments & MR & $1(2.2)$ & $1(6.7)$ & 7 \\
\hline Translocate individuals between areas & M & $1(2.2)$ & $1(6.7)$ & 0 \\
\hline Use of playbacks to attract individuals to unoccupied habitats & M & $1(2.2)$ & $1(6.7)$ & 1 \\
\hline
\end{tabular}

${ }^{1} \mathrm{M}$, management; MR, monitoring and research; RL, regulation and legislation.

${ }^{2}$ IBA, Important Bird Area; SPA, Special Protection Area.

TABLE 2 Number of conservation measures for Dupont's lark applied by regional governments in Spain. Number of males and proportion of the occupancy area of all populations included in Special Protection Areas (SPAs) and Important Bird Areas (IBAs) in each region are also shown, extracted from Suárez (2010), Pérez-Granados and López-Iborra (2013) and Gómez-Catasús et al. (2018). Annual change rate of the population (\%) for each region was taken from Gómez-Catasús et al. (2018).

\begin{tabular}{llllll}
\hline Regional government & No. of males & $\begin{array}{l}\text { \% of occupancy } \\
\text { area in SPAs }\end{array}$ & $\begin{array}{l}\text { \% of occupancy } \\
\text { area in IBAs }\end{array}$ & $\begin{array}{l}\text { Change rate of } \\
\text { population (\%) }\end{array}$ & $\begin{array}{l}\text { Conservation } \\
\text { measures applied }\end{array}$ \\
\hline Andalusia & 26 & 2 & 30 & -10.9 & 7 \\
Aragon & 1,898 & 35 & 38 & 1.5 & 7 \\
Castile-Leon & 1,323 & 38 & 44 & -8.4 & 12 \\
Castile-La Mancha & 653 & 13 & 30 & 1.5 & 6 \\
Catalonia & 7 & 100 & 100 & -8.7 & 8 \\
Region of Murcia & 35 & 0 & 35 & 2.6 & 2 \\
Navarre & 60 & 1 & 100 & -1.1 & 6 \\
Community of Valencia & 52 & 69 & & -2.5 & 6 \\
\hline
\end{tabular}

availability was considered important for protecting marginal habitats.

We selected four axes (77.8\% of the total variance) to identify the reasons for not implementing conservation interventions (Supplementary Table 4, summary of PCA in Supplementary Table 6). The first axis (PCA Ib, $33.1 \%$ of total variance) defined a gradient between conservation interventions that were not implemented on the basis of legal obstacles and elusive answers (negative coordinates) and those that were not implemented because of budget and time limitations (positive coordinates). PCA IIb $(16.8 \%$ of total variance) defined a gradient between interventions 


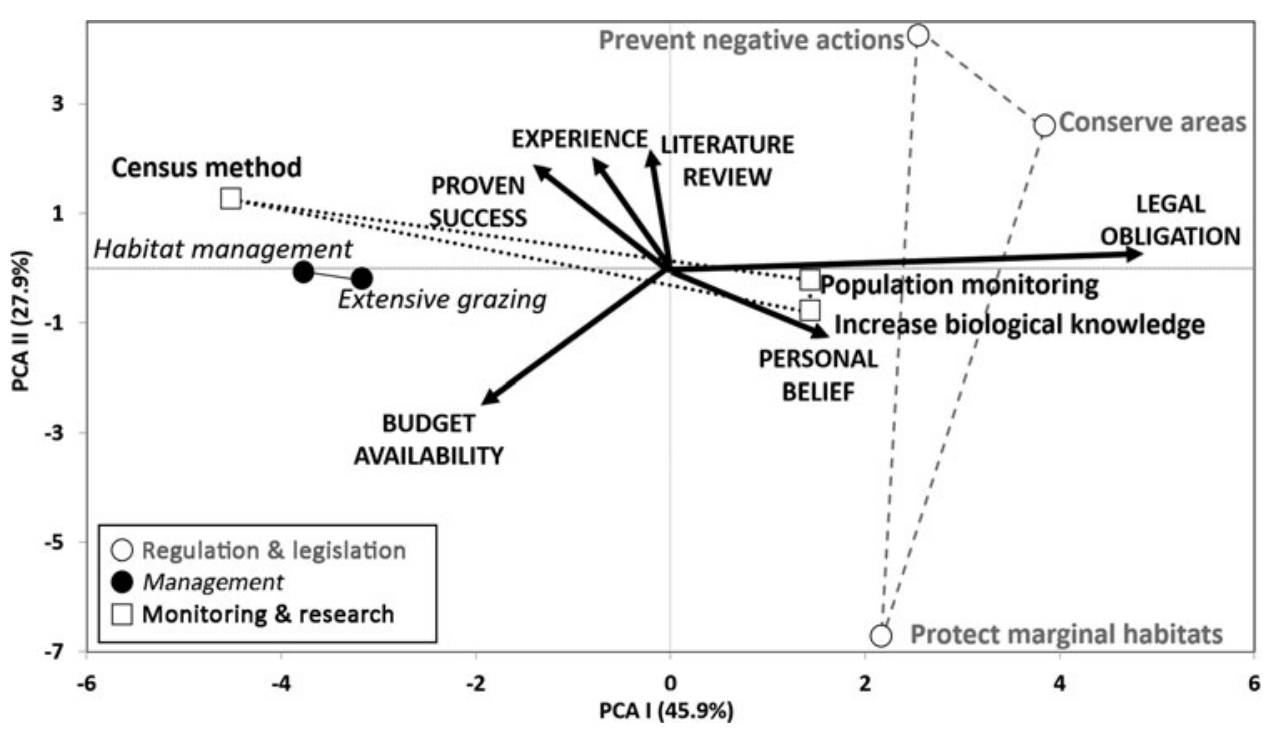

FIG. 1 Principal component analysis (PCA) ordination of conservation interventions to protect Dupont's lark Chersophilus duponti based on the reasons given for their implementation. Arrows show factor scores for reasons (identified by capital letters) correlated to at least one axis with $\mathrm{P}<$ o.1. The type of intervention is identified by different symbols and fonts. Polygons are drawn around interventions of the same type. that were not implemented because they were unknown or considered unnecessary (negative coordinates) and those that were declared to be in process (positive values). Management interventions were grouped on the positive side of PCA Ib, together with the only monitoring activity analysed. Reasons given for not implementing regulation interventions were more variable than those declared for not implementing management interventions, and both types of conservation interventions were spatially distributed along PCA IIb (Fig. 2a). The third axis (PCA IIIb, $15.7 \%$ of total variance) placed on negative coordinates those conservation interventions not implemented mainly because of managers' doubts about their efficacy (Fig. 2b). The fourth axis (PCA IVb, $12.2 \%$ of total variance) was positively associated with time limitations and technical difficulties and negatively correlated with shortage of technical staff. Overall, axes PCA IIIb and IVb separate management from regulation interventions almost perfectly (Fig. 2b). In summary, the PCA indicated that management interventions were not implemented mainly because of a combination of technical difficulty, doubts about their efficacy, a lack of studies demonstrating their efficacy, and time and budget limitations. Reasons for not implementing regulation interventions were more heterogeneous. This intervention type most frequently received 'in progress' or elusive answers, and was the only type for which legal obstacles were noted.

The correlation between the number of interventions applied and the size of the population of Dupont's lark in each region (Spearman's correlation coefficient $=0.098$; $\mathrm{P}=0.817$ ), or the proportion of populations included in Important Bird Areas (Spearman's correlation coefficient = $0.565, \mathrm{P}=0.144$ ) or in Special Protection Areas (Spearman's correlation coefficient $=0.638, \mathrm{P}=0.088$ ), were not significant (Table 2). However, the number of conservation interventions applied and annual rate of change of the population in each region showed a marginally significant negative correlation (Spearman's correlation coefficient $=-0.867 ; \mathrm{P}=0.054$ ), with a larger number of conservation interventions implemented in those regions where populations were declining most rapidly (Fig. 3).

\section{Discussion}

Dupont's lark is a well-studied passerine, and there is consensus among scientists on the conservation interventions that should be implemented to protect the species. However, there is a large conservation research-practice gap, revealed by the disparity between the actions proposed by scientists and those frequently implemented by managers. Scientists mainly proposed regulation/legislation and management interventions ( $45 \%$ and $42 \%$ of the proposed interventions, respectively), whereas managers mainly implemented monitoring and research interventions (50\% of interventions). Management interventions were most under-represented in practice, with only $20 \%$ of the implemented interventions.

Understanding why managers implement or do not implement certain conservation interventions is useful to help reduce the conservation research-practice gap currently affecting Dupont's lark. Regulation and legislation measures were mainly implemented because of legal obligations and managers' beliefs about these types of measures. These reasons were also important for implementing long-term monitoring programmes and increasing knowledge about the biology of the species, which are two of the monitoring and research interventions. Regional authorities are required to provide periodic updates of population estimates of threatened species, which may explain the motivations for implementing such research interventions. Developing a precise counting method and the two management interventions 

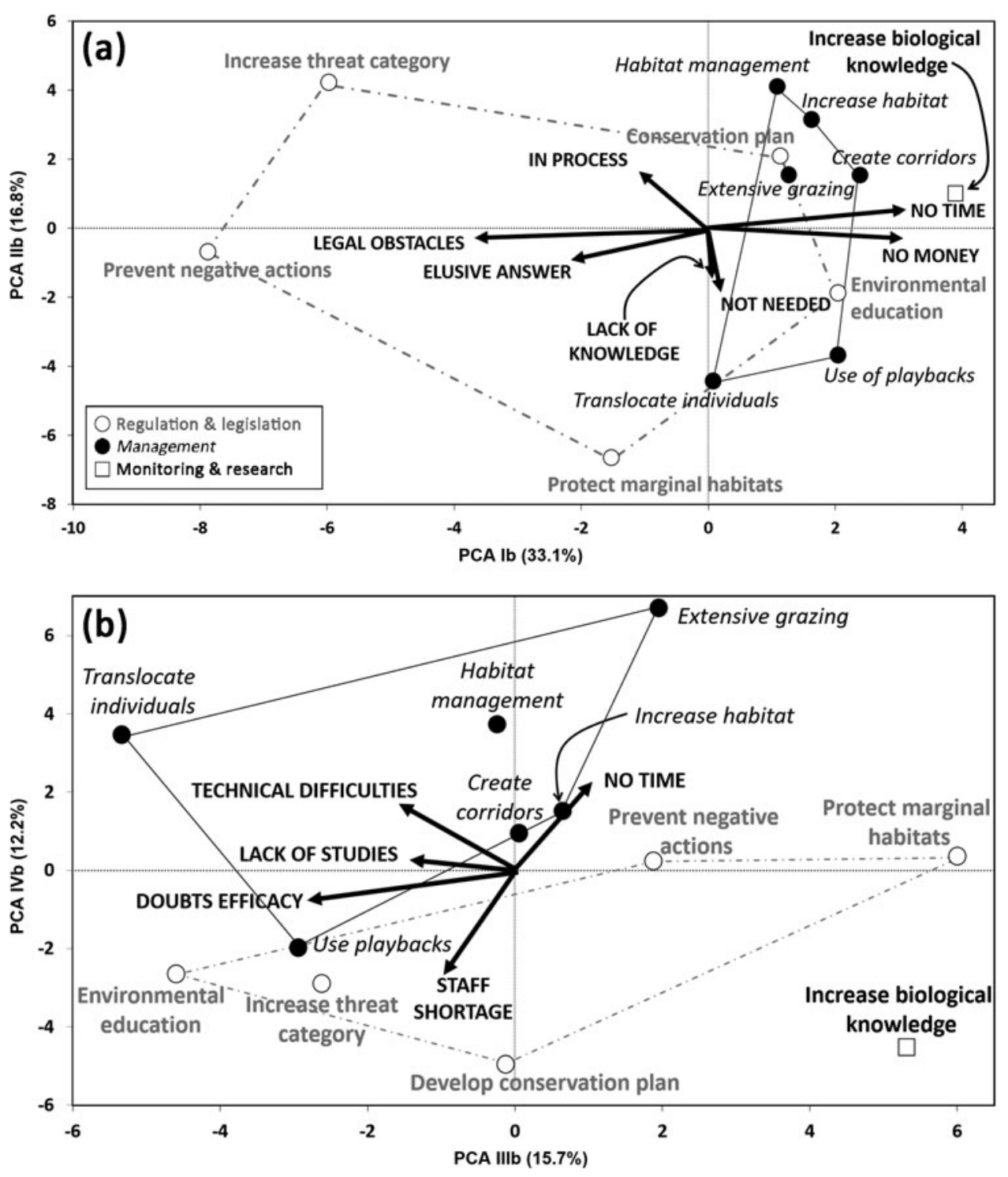

FIG. 2 PCA ordination of conservation interventions to protect Dupont's lark based on the reasons given for a lack of implementation. Arrows show factor scores for reasons (identified by capital letters) correlated to at least one depicted axis with $\mathrm{P}<0.1$. (a) Ordination of the first two axes; (b) ordination of the third and fourth axes.

The types of intervention are identified by different symbols and fonts. Polygons are drawn around interventions of the same type. (habitat management and extensive grazing) appear to be implemented when a budget is available and there are known similar experiences with positive results. This highlights the importance of performing studies on the efficacy of the conservation interventions implemented, which would allow managers to select the most appropriate ones. In addition, these studies would provide the scientific evidence that managers seem to need to increase the likelihood of implementing management interventions (Gibbons et al., 2011).

The reasons hindering the implementation of regulatory and legislation measures were varied. Among the most important reasons were legal obstacles, presumably caused by legal conflicts, technical difficulties and staff shortages. Reasons categorized as 'elusive answers' were only given for regulation and legislation interventions, and 'in progress' reasons were also common. This suggests managers face challenges in getting approval for regulatory and legislation measures, which may depend on politicians or managers in other departments. Thus, finding solutions to reduce the gap for regulatory and legislative measures will be particularly difficult. Some regulatory and legislative measures, such as increasing the threat category of the species, have never been implemented, and others, such as the development of a conservation action plan, have been implemented only once. The latter is of particular concern, because according to Spanish legislation, every region should have developed a conservation plan since 2004, when the species was categorized as Vulnerable. The establishment of conservation plans for the species in Spain could contribute to narrowing the research-practice gap, as this should lead to the implementation of conservation interventions. Regardless, the approval of a conservation plan alone will not have a direct effect on improving a species' status unless it is implemented effectively and the efficacy of the conservation interventions is evaluated (Bottrill et al., 2011). 


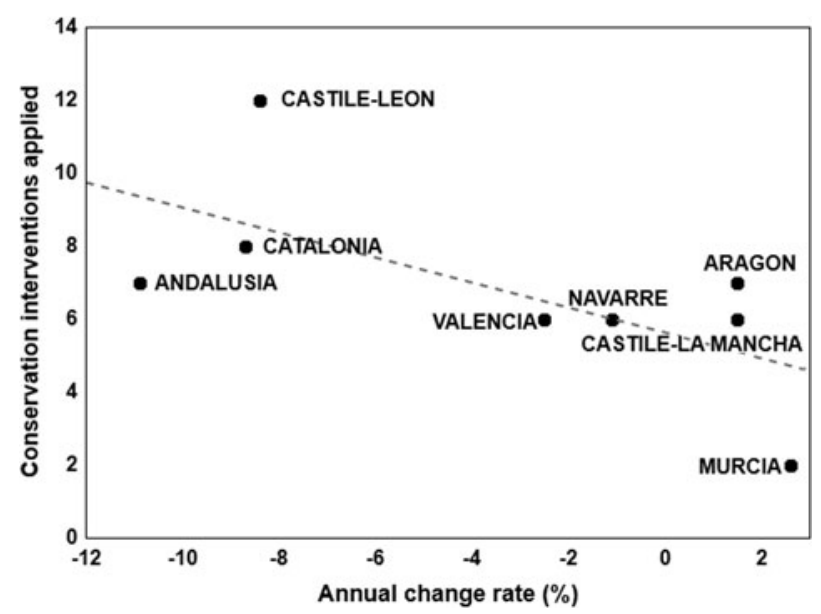

FIG. 3 Relationship between the number of conservation measures applied and the annual rate of change in each region where Dupont's lark occurs. Annual change rate (\%) for each region was extracted from Gómez-Catasús et al. (2018). The dashed line shows the linear relationship between the two variables.

A major factor in the conservation research-practice gap for Dupont's lark is the limited number of management interventions implemented. Our results identified budget and time limitations as the main reasons why managers did not implement management interventions. These interventions can be expensive and logistically difficult (Bertuol-García et al., 2018; Walsh et al., 2019) because they often require additional staff and equipment, and necessitate monitoring the effectiveness of the conservation measure applied (Shea et al., 2002; Scott et al., 2010). Therefore, scientific studies testing the effectiveness of different measures in different conditions are paramount to deciding where to invest limited resources.

Because most management interventions have rarely been implemented, there is no information about their performance in practice, or their potential for improvement or adaptation to different contexts. This creates a vicious circle: scientists propose interventions based on expert opinion and limited knowledge of the biology of the species, without empirical evidence of their effectiveness, and managers are reluctant to make interventions that have been recommended on the basis of untested hypotheses, because of the high costs and the amount of time and technical studies required. Managers may thus prefer to invest in conservation interventions for which the costs and benefits are known from experience (Fazey et al., 2005). To break this circle it is necessary to test all interventions that have been implemented, and disseminate the results, including negative results (Pérez-Granados \& Traba, 2019). Only then will practitioners be able to carry out evidence-based conservation (see Salafsky et al., 2019).

The variable most strongly correlated with the number of conservation interventions implemented in a region was the current population trend of the species, with a negative correlation. This suggests that conservation interventions are only implemented when the species urgently requires their application to avoid local extinction. In a previous study, Suárez (2010) also found several instances in which the most severely declining Dupont's lark populations were better protected. This is probably related to the difficulties of obtaining conservation funds and dedicated staff time for conservation when a species is not in severe decline.

Mismatches between science and practice for Dupont's lark appear to be the result of complex and diverse factors that go beyond poor communication. In addition, some causes seem to be interconnected, and vary between the types of conservation interventions, thus making it more difficult to reduce the research-practice gap. Where published studies evaluating the effectiveness of conservation interventions are lacking (Pérez-Granados \& Traba, 2019), those measures most often proposed by scientists could be considered as a priority to evaluate the effectiveness of conservation interventions. Improved communication and collaboration between scientists and managers responsible for Dupont's lark conservation in Spain need to be encouraged. Conservation biologists should devote more time and effort to transferring knowledge and conservation proposals to managers, by providing summarized research findings (Gossa et al., 2015; Walsh et al., 2015; Toomey et al., 2017). This collaboration should start by developing a common strategy to analyse the effectiveness of those conservation interventions already implemented and whose efficacy had been monitored but that have never been analysed or published. In addition, studies comparing the costs, benefits and risks of investments in each conservation measure need to be developed, to identify the most effective conservation interventions. This could save managers money and time, while achieving more conservation goals.

Acknowledgements We thank Emilio Climent for reviewing the questionnaire draft; all respondents for their contribution; Juan Traba for help in connecting with some respondents; and José Antonio González Novoa, Jesús T. García and one anonymous referee for their comments on the manuscript. This research was supported by the project 'Estudios aplicados a la conservación de la conservación de las poblaciones de alondra ricotí (Chersophilus duponti) en el entorno del municipio de Vallanca' and funded by Levantina y Asociado de Minerales, S.A.

Author contributions Study conception, literature search: CPG; classification of conservation interventions, preparation and distribution of questionnaires, data analysis, writing: both authors.

\section{Conflicts of interest None.}

Ethical standards This research abided by the Oryx guidelines on ethical standards. Data collection was conducted in compliance with the Spanish law of transparency, access to public information and good governance (Law 19/2013). 


\section{References}

Bertuol-Garcia, D., Morsello, C., N El-Hani, C. \& Pardini, R. (2018) A conceptual framework for understanding the perspectives on the causes of the science-practice gap in ecology and conservation. Biological Reviews, 93, 1032-1055.

Birdife International (2020) Chersophilus duponti. In The IUCN Red List of Threatened Species 2020: e.T22717380A173711498. dx.doi. org/10.2305/IUCN.UK.2020-3.RLTS.T22717380A173711498.en [accessed 28 January 2021].

Bottrill, M.C. \& Pressey, R.L. (2012) The effectiveness and evaluation of conservation planning. Conservation Letters, 5, 407-42O.

Bottrill, M.C., Walsh, J.C., Watson, J.E., Joseph, L.N., Ortega-Argueta, A. \& Possingham, H.P. (2011) Does recovery planning improve the status of threatened species? Biological Conservation, 144, 1595-1601.

Cook, C.N., Hockings, M. \& Carter, R. (2010) Conservation in the dark? The information used to support management decisions. Frontiers in Ecology and the Environment, 8, 181-186.

Cook, C.N., Mascia, N.B., Schwartz, M.W., Possingham, H.P. \& FUlLer, R.A. (2013) Achieving conservation science that bridges the knowledge-action boundary. Conservation Biology, 27, 669-678.

Dormann, F.C., Elith, J., Bacher, S., Buchmann, C., Carl, G., CARré, G. et al. (2013) Collinearity: a review of methods to deal with it and a simulation study evaluating their performance. Ecography, 36, 27-46.

Fabian, Y., Bollmann, K., Brang, P., Heiri, C., Olschewski, R., Rigling, A. et al. (2019) How to close the science-practice gap in nature conservation? Information sources used by practitioners. Biological Conservation, 235, 93-101.

Fazey, I., Fischer, J. \& Lindenmayer, D.B. (2005) What do conservation biologists publish? Biological Conservation, 124, 63-73.

Gibbons, D.W., Wilson, J.D. \& Green, R.E. (2011) Using conservation science to solve conservation problems. Journal of Applied Ecology, 48, 505-508.

Gómez-Catasús, J., Pérez-Granados, C., Barrero, A., Bota, G., Giralt, D., LÓpez-Iborra, G.M. et al. (2018) European population trends and current conservation status of an endangered steppe-bird species: the Dupont's lark Chersophilus duponti. PeerJ, 6, e5627.

Gossa, C., Fisher, M. \& Milner-Gulland, E.J. (2015) The research-implementation gap: how practitioners and researchers from developing countries perceive the role of peer-reviewed literature in conservation science. Oryx, 49, 80-87.

JACKSON, D.A. (1993) Stopping rules in principal components analysis: a comparison of heuristical and statistical approaches. Ecology, 74, 2204-2214.

Knight, A.T., Cowling, R.M., Rouget, M., Balmford, A., Lombard, A.T. \& CAMPBELL, B.M. (2008) Knowing but not doing: selecting priority conservation areas and the researchimplementation gap. Conservation Biology, 22, 610-617.

LEGGE, S. (2015) A plea for inserting evidence-based management into conservation practice. Animal Conservation, 18, 113-116.

Matzek, V., Covino, J., Funk, J.L. \& Saunders, M. (2014) closing the knowing-doing gap in invasive plant management: accessibility and interdisciplinarity of scientific research. Conservation Letters, 7, 208-215.

Oksanen, J., Kindt, R., Legendre, P., O’Hara, B., Stevens, M.H.H., Oksanen, M.J. \& Suggests, M.A. (2007) The vegan package. Community Ecology Package, 10, 631-637.

Pérez-Granados, C. \& López-Iborra, G.M. (2013) Census of breeding birds and population trends of the Dupont's lark (Chersophilus duponti) in Eastern Spain. Ardeola, 6o, 143-150.

Pérez-Granados, C. \& López-Iborra, G.M. (2018) Biology and conservation of the Dupont's Lark Chersophilus duponti. Revista Catalana d'Ornitologia, 34, 33-54.

Pérez-Granados, C. \& Traba, J. (2019) Testing the conspecific attraction hypothesis with Dupont's larks, a resident species of songbird in central Spain. Journal of Field Ornithology, 90, 277-285.

Pullin, A.S. \& KNight, T.M. (2005) Assessing conservation management's evidence base: a survey of management-plan compilers in the United Kingdom and Australia. Conservation Biology, 19, 1989-1996.

R Development Core Team (2014) R: a Language and Environment for Statistical Computing. R Foundation for Statistical Computing, Vienna, Austria. R-project.org [accessed 7 May 2020].

Salafsky, N., Boshoven, J., Burivalova, Z., Dubois, N.S., Gomez, A., Johnson, A. et al. (2019) Defining and using evidence in conservation practice. Conservation Science and Practice, 1, e27.

Scott, J.M., Goble, D.D., Haines, A.M., Wiens, J.A. \& Neel, M.C. (2010) Conservation reliant species and the future of conservation. Conservation Letters, 3, 91-97.

Shea, K., Possingham, H.P., Murdoch, W.W. \& Roush, R. (2002) Active adaptive management in insect pest and weed control: intervention with a plan for learning. Ecological Applications, 12, 927-936.

Suárez, F. (ed.) (2010) La Alondra Ricotí, Chersophilus duponti. Dirección General para la Biodiversidad. Ministerio de Medio Ambiente y Medios Rural y Marino, Madrid, Spain.

Sutherland, W.J., Pullin, A.S., Dolman, P.M. \& Knight, T.M. (2004) The need for evidence-based conservation. Trends in Ecology and Evolution, 19, 305-308.

Sutherland, W.J., Adams, W.M., Aronson, R.B., Aveling, R., BlackBurn, T.M., BROAD, S. et al. (2009) One hundred questions of importance to the conservation of global biological diversity. Conservation Biology, 23, 557-567.

Sutherland, W.J., Spiegelhalter, D. \& Burgman, M.A. (2013) Policy: twenty tips for interpreting scientific claims. Nature, 503, 335-337.

Toomey, A.H., Knight, A.T. \& BArlow, J. (2017) Navigating the space between research and implementation in conservation. Conservation Letters, 10, 619-625.

Walsh, J.C., Dicks, L.V., Raymond, C.M. \& Sutherland, W.J. (2019) A typology of barriers and enablers of scientific evidence use in conservation practice. Journal of Environmental Management, 250, 109481.

Walsh, J.C., Dicks, L.V. \& Sutherland, W.J. (2015) The effect of scientific evidence on conservation practitioners' management decisions. Conservation Biology, 29, 88-98. 